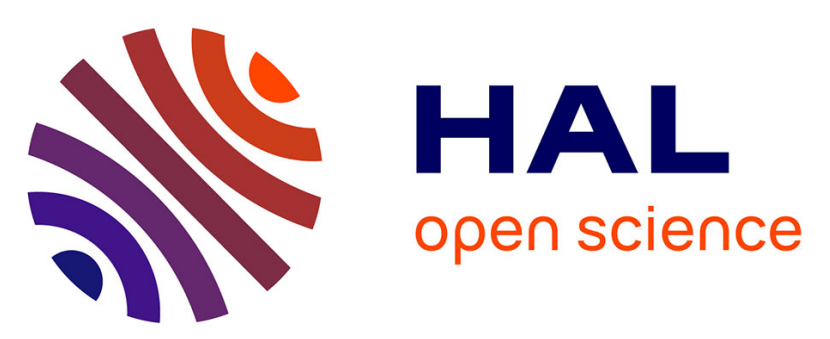

\title{
A mean field model of the decrease of the specific surface area of dry snow during isothermal metamorphism
}

\author{
Loïc Legagneux, Florent Domine
}

\section{To cite this version:}

Loï Legagneux, Florent Domine. A mean field model of the decrease of the specific surface area of dry snow during isothermal metamorphism. Journal of Geophysical Research, 2005, 110 (F04011), 1 à 12 p. 10.1029/2004JF000181 . insu-00374624

\section{HAL Id: insu-00374624 \\ https://hal-insu.archives-ouvertes.fr/insu-00374624}

Submitted on 19 Feb 2021

HAL is a multi-disciplinary open access archive for the deposit and dissemination of scientific research documents, whether they are published or not. The documents may come from teaching and research institutions in France or abroad, or from public or private research centers.
L'archive ouverte pluridisciplinaire HAL, est destinée au dépôt et à la diffusion de documents scientifiques de niveau recherche, publiés ou non, émanant des établissements d'enseignement et de recherche français ou étrangers, des laboratoires publics ou privés. 


\title{
A mean field model of the decrease of the specific surface area of dry snow during isothermal metamorphism
}

\author{
Loïc Legagneux and Florent Domine \\ Laboratoire de Glaciologie et Géophysique de l'Environnement, CNRS, St Martin d'Hères, France
}

Received 11 June 2004; revised 13 April 2005; accepted 26 August 2005; published 18 November 2005.

[1] The surface area of snow that is accessible to gases is an essential parameter for quantifying the exchange of trace gases between the snowpack and the atmosphere and is called the specific surface area (SSA). Snow SSA decreases during metamorphism, but this is not described in current snow models owing to the complexity of the physics and geometry of snow. In this paper, we test whether it is possible to model snow SSA changes during isothermal metamorphism without accounting for all the complexity of the three-dimensional (3-D) structure of real snow. We have developed a mean field model of snow metamorphism under isothermal conditions, grounded in the theoretical framework of transient Ostwald ripening and representing snow as a distribution of spherical particles. Analytical expressions of the growth rates of these spheres are obtained, and the evolution of two measurable parameters that characterize snow geometry, the SSA and the distribution of radii of curvature (DRC), are simulated and compared to experimental data obtained by X-ray tomography. The qualitative effects of temperature, snow density, and the condensation coefficient on the rate of SSA decrease are examined. The model predicts very well the rate of evolution of the particle size distribution, which validates our physical description of isothermal metamorphism. In particular, we find that vapor phase diffusion is rate limiting. However, the calculation of the SSA from the DRC appears delicate and evidences too crude approximations in our description of the 3-D geometry of snow. Finally, it is stressed that the initial DRC can greatly influence the rate of SSA decrease, while experimental measurements of the rate of SSA decrease suggest that all snow types evolve in a similar way. It is thus proposed that most natural fresh snows have similar DRCs.

Citation: Legagneux, L., and F. Domine (2005), A mean field model of the decrease of the specific surface area of dry snow during isothermal metamorphism, J. Geophys. Res., 110, F04011, doi:10.1029/2004JF000181.

\section{Introduction}

[2] Many scientific fields such as avalanche forecasting, remote sensing, meteorology, climatology or atmospheric chemistry are directly concerned by the structural and microphysical properties of the snow cover [Colbeck, 1991]. Snowpacks are porous materials and their physical properties such as mechanical strength [Durand et al., 1999], optical absorption and emissivity [Grenfell and Warren, 1999; Schwander et al., 1999; Mätzer, 2002], heat and mass transport [Sturm, 1989; Arons and Colbeck, 1995; Albert, 1996], species transport [Albert, 1995], and air-snow interactions [Dominé and Shepson, 2002] are therefore intimately related to their structural features. Snow properties have to be quantified accurately, but snow undergoes continuous morphological changes [De Quervain, 1958; Colbeck, 1982, 1997; Sokratov, 2001; Dominé et al., 2002; Cabanes et al., 2002], essentially because of the high saturating vapor pressure of ice as compared to other materials at ambient temperature that allows important

Copyright 2005 by the American Geophysical Union. 0148-0227/05/2004JF000181 water vapor fluxes to take place. The mechanical and thermodynamical processes involved in these changes in shape, size and structure are regrouped under the term "metamorphism" [Maeno and Ebinuma, 1983]. Snow metamorphism needs to be understood to predict the evolution of snow properties.

[3] Metamorphism is the response of a three-dimensional dynamic material, snow, to external thermodynamical constraints such as heat fluxes and temperature gradients, and mechanical constraints such as accumulation and wind. A detailed model of metamorphism intended to predict the evolution of all snow properties must be grounded on a proper description of both the geometry of snow and of the physical processes responsible for metamorphism. This ideal model is at present not attainable because of the variety and the complexity of both the physical processes [De Quervain, 1958; Colbeck, 1973, 1980, 1982, 1983a, 1983b; Akitaya, 1974; Raymond and Tusima, 1979; Marbouty, 1980; Brun, 1989; Sturm and Benson, 1997] and the complex 3-D structural features of snow [Colbeck, 1986, 1991; Fierz and Baunach, 2000]. Therefore the current models concentrate on a given aspect of snow metamorphism and on a given set of snow properties. They 
try to reproduce satisfactorily this set of features from suitable approximations [Brun et al., 1989, 1992; Brown et al., 1994; Bullard, 1997; Dang et al., 1997; Baunach et al., 2001; Flin et al., 2003; Jordan, 1991]. These mandatory choices are responsible for a lack of information on those properties of snow that do not coincide with the priorities of the model.

[4] The specific surface area of snow (SSA), for example, is the surface area of ice accessible to gases per unit mass of snow [Legagneux et al., 2002]. Recent field studies have shown that it decreases from more than $1500 \mathrm{~cm}^{2} \mathrm{~g}^{-1}$ to less than $100 \mathrm{~cm}^{2} \mathrm{~g}^{-1}$ over a season, because of metamorphism [Cabanes et al., 2002, 2003; Legagneux et al., 2002]. Trace gases exchanges and phase transitions occur along this surface area. Obviously, this geometrical parameter is of prime importance for the quantification of the air-snow interactions in seasonal snowpacks [Dominé et al., 2002] and also for the determination of the rate of metamorphism [Sokratov, 2001]. However, no model of snow physics has ever been devoted to snow SSA. More generally, the difficulty of describing the 3-D properties of snow crystals has not yet been overcome because they are difficult to measure and to include in models. For example, none of the aforementioned models does account for the distribution of radii of curvature (DRC), with one exception [Flin et al., 2003]. However, the DRC is probably important to model metamorphism, since a large and a small grain do not behave like a pair of grains of intermediate size.

[5] At present, the most complete description of snow geometry and of its evolution during metamorphism has been reported by Flin et al. [2003], who proposed a 3-D reconstruction of the structure of snow based on tomographic data. The interest of their model lies in the exact description of the microstructure of snow that yields evolutions of snow SSA and DRC at various time intervals. This accurate geometrical description has in compensation both practical and theoretical drawbacks: (1) the great computational time and complexity on a 3-D mesh, (2) a subsequently limited description of the physics of metamorphism that, for example, does not include vapor phase diffusion, (3) the need to obtain synchrotron beam time to acquire the necessary highresolution tomographic data, and (4) long and difficult data analysis to obtain 3-D images. Computing limitations until now have prevented a thorough exploitation of an exact description of snow geometry in models of snow metamorphism. Moreover, models of snow metamorphism that predict snow SSA may be intended to be coupled to atmospheric chemistry models [Dominé and Shepson, 2002], and there is thus a need to find a fairly simple manner to model snow SSA, even if acceptable approximations have to be made.

[6] In a previous study [Legagneux et al., 2004], we reported experiments that showed empirically that the decrease in SSA of snow under isothermal conditions was surprisingly well fitted by simple mathematical functions of the form $\mathrm{SSA}=\mathrm{B}-\mathrm{A} \operatorname{Ln}(\mathrm{t}+\Delta \mathrm{T})$, where $\mathrm{t}$ is time and $\mathrm{A}, \mathrm{B}$, and $\Delta \mathrm{t}$ are adjustable parameters. We further demonstrated [Legagneux et al., 2004] that this equation could in fact be derived from the theory of Ostwald ripening. This theory [Lifshitz and Slyozov, 1961; Wagner, 1961] originally described the coarsening (i.e., increase in size) of solid particles in a liquid phase. Its driving force is the minimization of the energy of the system by reduction of the interfacial area. Coarsening occurs by dissolution of small particles, diffusion in the liquid phase and growth of large particles. The isothermal metamorphism of dry snow shows many physical similarities with Ostwald ripening: large grains grow at the expense of small grains and transfer of matter is by transport through air, which can be regarded as the "solvent" phase. Surely snow metamorphism is more complex than Ostwald ripening since snow particles may be in touch and interact directly through other processes [Maeno and Ebinuma, 1983] such as the transfer of matter in the solid state at grain boundaries [Colbeck, 1997, 1998, 2001]. However, the fact that our observations indicate that seasonal snow follows Ostwald ripening law is a strong indication that those other processes can, to a first approximation and at least in seasonal snowpacks, be neglected in a quantitative description of snow grain coarsening and SSA reduction.

[7] In this paper, we therefore pursue our demonstration of this idea by producing a mean field model of the isothermal metamorphism of snow, based on the physics of Ostwald ripening. We describe snow as a distribution of spherical particles. This may seem as a crude approximation, but we test here its validity and limitations in detail. Our intention is to see whether the evolution of the SSA and the DRC of snow under isothermal conditions can be reproduced satisfactorily with such an elementary geometrical model, or if a more detailed description of the structural features is necessary.

\section{Model}

[8] This model relies on the physical processes involved in the theories of Ostwald ripening and we first recall them briefly.

\subsection{Ostwald Ripening}

[9] Ostwald ripening describes the coarsening of a distribution of particles by exchange of matter through a liquid phase. Lifshitz and Slyozov [1961] and Wagner [1961] first addressed this problem quantitatively. Their treatment, known as the LSW theory, relies on the following hypotheses. (1) The driving force is the minimization of the total interfacial energy; large particles thus grow at the expense of small particles. (2) The diffusive transport of matter through the liquid phase is in steady state. (3) The particles are spherical, disconnected and the solid volume fraction tends to zero so that the diffusion field around any particle is not disturbed by the others and can be considered spherical. (4) The surface processes of incorporation of molecules into the particles are those of a rough interface; that is, any molecule that hits the surface of the particle becomes incorporated into the lattice.

[10] Lifshitz and Slyozov [1961] assumed that the diffusion step was rate limiting, whereas Wagner [1961] assumed that the surface processes were rate limiting. In both cases, they demonstrated that the system evolved toward a steady state regime. This steady state is characterized by (1) a particle size distribution (PSD) which is stationary when normalized to the mean grain radius and 
(2) the mean grain radius, $R_{c}$, that follows a simple law of evolution (1):

$$
R_{c}^{n}-R_{0}^{n}=K t
$$

where $R_{0}$ is the initial mean grain radius at time $t=0, n$ is the growth exponent and $\mathrm{K}$ is the growth rate. Wagner's hypothesis yielded $n=2$, against $n=3$ for that of Lifshitz and Slyozov. An analytical expression of $\mathrm{K}$ could be derived in both cases. Finally, the shape of the steady state PSD is entirely defined by the three parameters $R_{0}$, $n$, and $\mathrm{K}$.

[11] Many studies extended the field of application of the LSW theory to the case of nonzero fractions of solid [Brailsford and Wynblatt, 1979; Marqusee and Ross, 1984; Akaiwa and Voorhees, 1994] or to nonspherical particles [De Hoff, 1984, 1991]. They obtained the same rate equation (1) and reached the same general conclusions concerning the characteristics of the steady state and especially the value of $n$. They also showed that the stationary PSD and the growth rate $\mathrm{K}$ depended on the fraction of solid and on the shape of the particles. Legagneux et al. [2004] indicated that an equivalent expression could be derived from (1) that gives the specific surface area SSA of a distribution of ice particles:

$$
\operatorname{SSA}=\operatorname{SSA}_{0}\left(\frac{\tau}{t+\tau}\right)^{\frac{1}{n}}
$$

where $\mathrm{SSA}_{0}$ is the initial SSA at time $\mathrm{t}=0$ and $\tau$ is given by

$$
\tau=\frac{1}{K}\left(\frac{3 f}{\rho_{\text {ice }} \mathrm{SSA}^{0}}\right)^{n}
$$

In this last expression, $\rho_{\text {ice }}$ is the density of ice and $\mathrm{f}$ is a form factor assumed constant that accounts for nonspherical shapes.

\subsection{Physics}

[12] The theoretical assumptions grounding our model and detailed in this section are the following: (1) the evolution is isothermal, (2) matter transfer takes place in the gas phase and (3) it follows the equations of steady state diffusion, (4) the condensation coefficient is set equal to 1 , and (5) thermal conductivity is infinite. As discussed in a previous paper [Legagneux et al., 2004], the physics of snow metamorphism are very similar to those of Ostwald ripening, replacing the liquid phase by air and the solute concentration by the partial pressure of water. In fact, isothermal metamorphism is driven by the minimization of the surface area of the ice-air interface [Colbeck, 1980]. The vapor fluxes are therefore driven by the pressure gradients induced by the heterogeneities of curvature according to Kelvin's law:

$$
P_{\text {sat }}\left(T, R_{C}\right)=P_{\text {sat }}(T, \infty) \exp \left[\frac{2 \gamma V_{i}}{R T} \frac{1}{R_{C}}\right]
$$

$\mathrm{P}_{\text {sat }}\left(T, R_{c}\right)$ and $P_{s a t}(T, \infty)$ are the saturating vapor pressures of ice over a surface of radius of curvature $R_{c}$ and over a flat surface respectively. $\gamma$ is the interfacial energy of the ice-air interface assumed independent of the crystallographic orientation, $\mathrm{V}_{\mathrm{i}}$ is the molar volume of ice, $\mathrm{T}$ is temperature and $\mathrm{R}=8.31 \mathrm{~J} \mathrm{~mol}^{-1} \mathrm{~K}^{-1}$ is the gas constant.

[13] It is now widely accepted that the transfer of matter in the snowpack occurs mainly through the gas phase [Colbeck, 1982]. The fluxes of water vapor can be decomposed into two steps: (1) the grains undergo sublimation/ condensation cycles, and (2) the water molecules diffuse in the gas phase from one grain to another. The steady state approximation applies to the diffusion field, so that it verifies Laplace's equation (5):

$$
\Delta P=0
$$

This is again consistent with the physics of Ostwald ripening. Vapor diffusion and surface kinetics are modeled by Fick's (6) and Knudsen's (7) laws, respectively:

$$
\begin{gathered}
J_{d}=-\frac{D_{g}}{R T} \nabla P \\
J_{s}=-\alpha \frac{P_{s}-P_{s a t}\left(T, R_{c}\right)}{\sqrt{2 \pi R T M_{W}}}
\end{gathered}
$$

$\mathrm{J}_{\mathrm{d}}$ is the molar flux of water vapor that diffuses in response to a pressure gradient $\nabla \mathrm{P}, \mathrm{D}_{\mathrm{g}}$ is the diffusion coefficient of water molecules in air. $\mathrm{J}_{\mathrm{s}}$ is the molar flux of water vapor that is incorporated into the crystal, $\mathrm{M}_{\mathrm{W}}$ is the molar mass of water, $P_{s}$ is the partial pressure of water at the crystal surface, and $\alpha$ is the condensation coefficient that represents the ratio of molecules effectively incorporated into the ice matrix to these that impinge on the surface of the grain.

[14] The value of $\alpha$ is essential to quantify the kinetics of the surface processes that rule the incorporation of water vapor molecules into bulk snow. It strongly depends on the nature of the ice-air interface and on the growth mechanism. If the interface is rough, as assumed in Ostwald ripening theories, $\alpha=1$. Following Nelson and Knight [1998], ice crystals probably grow mostly by layer nucleation. Analytical expressions of $\alpha$ exist for stepped growth on flat faces by layer nucleation. In the snowpack, however, some grains are facetted, some are rounded and others are partially facetted and partially rounded [Colbeck, 1982; Dominé et al., 2003]. Moreover, other mechanisms such as growth from spiral steps cannot be totally excluded [Colbeck, 1983b; Dominé et al., 2003]. Consequently, no general expression of $\alpha$ is presently available that would apply during growth and sublimation, for both facetted and rounded grains, in a large range of temperatures and supersaturations. Awaiting more information, we use here $\alpha=1$.

[15] Finally, growth or sublimation generate latent heat fluxes that must be evacuated to avoid surface warming or cooling. They cannot be neglected for growth in air where the heat fluxes must be evacuated through the gas phase. Brown et al. [1994] did not neglect them in the snowpack either, but they also considered that heat was removed through the gas phase. We choose to neglect them, considering (1) that the isothermal evolution is very slow and thus the heat fluxes are very small and (2) above 


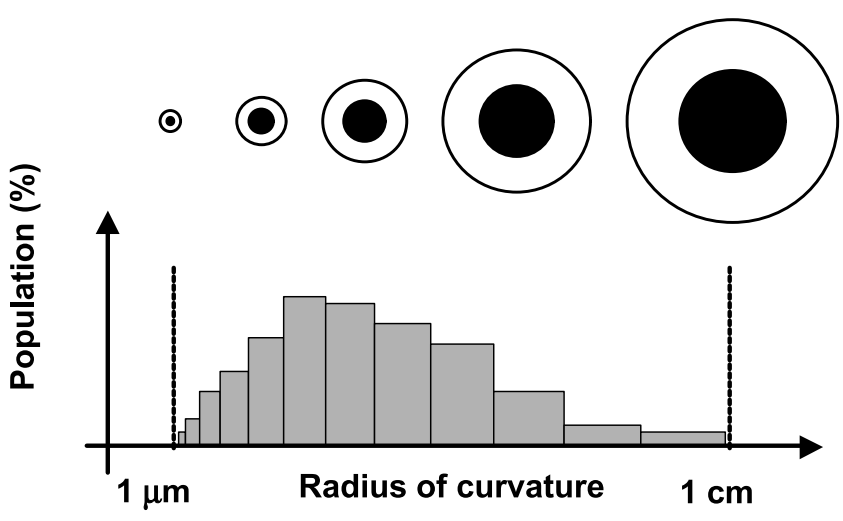

Figure 1. Description of snow as a distribution of spherical particles of radius $R_{c}$ placed at the center of spherical cavities of radius $R_{\text {cav }}$. $R_{\text {cav }}$ is proportional to $R_{c}$. Grain radii range from $1 \mu \mathrm{m}$ up to $1 \mathrm{~cm}$. The width of each size class is proportional to its mean grain radius.

all that the ice lattice in the snowpack evacuates heat efficiently.

\subsection{Geometry}

[16] The geometrical simplifications grounding our model and detailed in this section are the following: (1) PSDs are replaced by functions suitable for snow, (2) mean field description of the environment of a single grain, (3) the model deals with spherical disconnected particles, (4) the width of the particle size intervals is proportional to the particle size, and (5) concave structures are neglected.

[17] The general framework of Ostwald ripening appears to describe well most aspects of the physics of snow metamorphism, but it does not describe the geometry of snow. In particular, the PSD that characterizes a distribution of spherical particles obviously does not apply to the 3-D network encountered in snow. Some PSDs can be defined in snow from stereological measurements [Perla et al., 1986], but they clearly suffer from large approximations on crystals shapes and orientations. Moreover, we may wonder what the definition of the grain radius really is in the case of fresh snow. The DRC gives the very same information as the PSD for a distribution of spherical particles. However, the DRC unlike the PSD can also be defined and determined experimentally for snow, for example from 3-D tomography [Brzoska et al., 1999; Lundy et al., 2002]. In what follows, we will therefore consider the DRC of snow, and use it as the equivalent of the PSD in our use of the theory of Ostwald ripening.

[18] The general problem of the 3-D representation of a real material has two usual solutions. One of them is to pick up a representative sample of the studied medium and the second one consists in averaging the properties of the studied medium.

[19] The first option has been used frequently to model Ostwald ripening because spherical nonconnected particles are fully represented by their radius and the coordinates of their center [Marqusee and Ross, 1984; Voorhees and Glicksmann, 1984a, 1984b; Marder, 1985; Akaiwa and Voorhees, 1994]. In fact, the spherical shape allows solving the equations of diffusion through simplifying approxima- tions. The spatial resolution and statistical soundness of the model are then limited by the computer performance and the computational time.

[20] The second option imposes the same averaged environment to all grains and yields the growth rate of a given grain independently from its true immediate environment, implicitly assuming that statistically unlikely events are not amplified [Brailsford and Wynblatt, 1979; Stevens and Davies, 2002].

[21] Describing in detail the 3-D geometry of snow, as done by Flin et al. [2003], belongs at first sight to the first category of solutions. In the case of snow, however, a continuous matrix must be represented. Grains are interconnected and nonspherical, which prevents the use of simplifying approximations to solve the equations of diffusion. Moreover, the size of the structures encountered in snow ranges from a few microns to a few millimeters [Dominé et al., 2003] and this imposes to compute the equations over a 3-D mesh with a high resolution. As a consequence and in order to reduce the computational time, Flin et al. [2003] at present do not solve the equations of diffusion. They actually calculate the growth rates from mean field calculations where diffusion and surface kinetics are not accounted for.

[22] The model presented here is a mean field model derived from that of Brailsford and Wynblatt [1979]. Figure 1 illustrates the geometrical hypothesis. Snow is described as a distribution of spheres of various radii. Any distribution can be accommodated. The size width of a given class of grains is proportional to the grain radius to minimize the computational time. The particle size distribution accounts for grain sizes between $1 \mu \mathrm{m}$ and $1 \mathrm{~cm}$ in agreement with snow crystals observations by scanning electron microscopy (SEM) that scarcely detected smaller or larger structures [Legagneux et al., 2003; Dominé et al., 2003]. In the model, each ice sphere is surrounded by a spherical cavity of air that represents the mean environment of the grain. The radius of the cavity $\mathrm{R}_{\text {cav }}$ is proportional to the grain radius $R_{c}$ and adjusted in such a way that the equivalent density of the system grain cavity equals the experimental snow density:

$$
R_{\text {cav }}=R_{c}\left(\frac{\rho_{\text {ice }}}{10^{3} d_{\text {snow }}}\right)^{\frac{1}{3}}
$$

where $\rho_{\text {ice }}=917 \mathrm{~kg} \mathrm{~m}^{-3}$ and $\mathrm{d}_{\text {snow }}$ is snow density. The model simulates the evolution of this distribution of spherical particles and the results are expressed as DRCs.

[23] We are aware that spherical grains in spherical cavities cannot represent concave structures such as holes or necks that exist in snow. Holes can probably be neglected since these structures are quite rare and should disappear quickly according to Kelvin's law. This is consistent with our observations of snow by SEM [Dominé et al., 2003]. On the other hand, necks are numerous and develop during metamorphism. Modeling necks requires at least a cylindrical diffusion field for which no analytical solution exists. Necks are topological features that cannot be defined independently from the touching grains that create them. Their evolution is intricately associated to that of the convexities that bound it. Accounting for necks is thus 


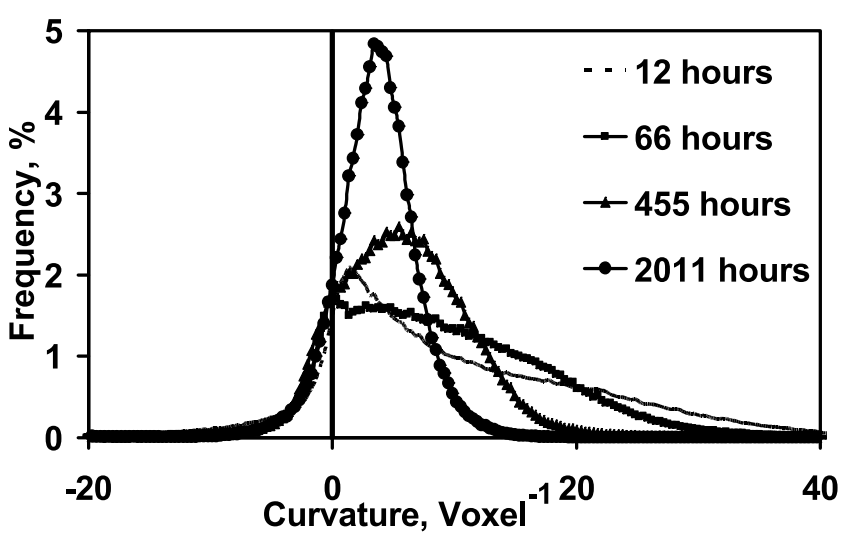

Figure 2. Curvature distribution of snow at given times during isothermal experiment at $-2{ }^{\circ} \mathrm{C}$ (data from Flin et al. [2004]). Concave structures (negative curvature) are less numerous than convex structures (positive curvature). One Voxel $=9.82 \mu \mathrm{m}$.

fundamentally incompatible with the principle of our model, namely separating the grain from its direct topological environment. It cannot be reconciled with the drastic simplification of a spherical symmetry. Estimating the effect of neglecting concavities will be the first goal of the model validation.

\subsection{Growth Rates}

[24] The huge interest of a spherical model is the possibility of calculating analytically the growth rate of a single grain. We define $\mathrm{P}_{\mathrm{av}}$, the partial pressure of water in the immediate vicinity of the cavity wall. The pressure field in the cavity is deduced from equations (5) and (8):

$$
P(r)=\frac{P_{a v} R_{c a v}-P_{s} R_{c}}{R_{c a v}-R_{c}}+\frac{R_{c}}{R_{c a v}}\left(P_{s}-P_{a v}\right)
$$

with $\mathrm{P}(\mathrm{r})$ and $\mathrm{P}_{\mathrm{s}}$ the pressures at distance $\mathrm{r}$ from the grain's center and at the surface of the grain. The diffusive flux toward the grain is then derived from (6) and (9). The flux of molecules eventually incorporated into the crystal is given by (4) and (7). The equality between these fluxes finally yields the growth rate $(10)$ by eliminating $\mathrm{P}_{\mathrm{s}}$ :

$$
\frac{d R_{c}}{d t}=\frac{M_{W}}{\rho_{\text {ice }}} \frac{P_{a v}-P_{\text {sat }}(T)\left(1+2 \frac{\gamma V_{L}}{R T R_{c}}\right)}{\frac{\sqrt{2 \pi M R T_{S}}}{\alpha}+\left(1-\frac{R_{c}}{R_{\text {cav }}}\right) \frac{R_{c}}{D_{g}} R T}
$$

Equation (10) can be interpreted as the ratio of the maximal flux of molecules, given by the Knudsen law, to a sum of terms that impede this flux. It is very close to that obtained by Nelson and Baker [1996] for the growth rate of ice crystals in the atmosphere, with three differences. (1) The supersaturations in isothermal snow are driven by Kelvin's law instead of thermal gradients. (2) The separation between grains is much higher in clouds than in deposited snow so that the corresponding cavity radius is infinite. (3) Heat removal in clouds is essentially via the gas phase and this adds a term of thermal impedance to the denominator.
[25] The growth rate of a given grain depends on the pressure imposed besides the cavity wall, $\mathrm{P}_{\mathrm{av}}$. The choice of $\mathrm{P}_{\mathrm{av}}$ is an important feature of this model. It arises from the condition of mass conservation. $\mathrm{P}_{\mathrm{av}}$ is taken as identical for all grains. It is set at any time in such a way that the sum of the individual gains and losses of mass on the overall distribution equals zero:

$$
\sum_{i}\left(N_{i} S_{i} \frac{d R_{c i}}{d t}\right)=0
$$

The label "i" identifies the class of grains of radius $R_{c i}, N_{i}$ is the number of grains of radius $R_{c i}$ and $S_{i}$ is the surface area of a given grain of radius $\mathrm{R}_{\mathrm{ci}}$. Combining (10) and (11) yields $\mathrm{P}_{\mathrm{av}}$ :

$$
P_{a v}=\frac{\sum_{i} N_{i} S_{i} A_{i}}{\sum_{i} N_{i} S_{i} B_{i}}
$$

$A_{i}$ and $B_{i}$ are constant functions of $R_{c i}$ whose exact expressions have no particular interest in what follows. As the grains grow or shrink, the shape of the DRC evolves, the $\mathrm{N}_{\mathrm{i}}$ change and consequently $\mathrm{P}_{\mathrm{av}}$ changes. The growth rate of any grain is determined at any time by the average pressure $\mathrm{P}_{\mathrm{av}}$, and therefore by the shape of the overall DRC.

\subsection{Procedure}

[26] The possibility of solving analytically the system of equations results in very short computational times. The following steps are repeated at each iteration: (1) The average pressure $P_{a v}$ is calculated from the DRC. (2) The gain or loss of mass is deduced from equation (9) in each class of grain size. (3) The DRC is modified to account for this mass change and for growing/shrinking grains that pass in the upper/lower class.

\section{Results and Discussion}

[27] This spherical mean field model allows calculating analytically the growth rate of a grain of any size, independently from its immediate environment. The condition of matter conservation yields the determination of the average pressure of water vapor $\mathrm{P}_{\mathrm{av}}$ which drives the growth. This already suggests that the shape of the DRC may greatly impact the growth rates. Before we discuss this more precisely, the validity of the model must be tested on real data to ensure that the geometrical approximations are not invalidating.

\subsection{Validation}

[28] The concave microstructures act as sinks of water vapor and should qualitatively lower the average vapor pressure $\mathrm{P}_{\mathrm{av}}$. They are not accounted for in the model but their proportion can be evaluated from 3-D tomographic observations of snow. Figure 2 reproduces the data from Flin et al. [2004] of the curvature distribution of a natural fresh snow sample from the French Alps, after 12, 66, 455, and 2011 hours of isothermal evolution at $-2^{\circ} \mathrm{C}$. Concave structures are obviously much less numerous than convex ones at any time and the evolution of their distribution does 

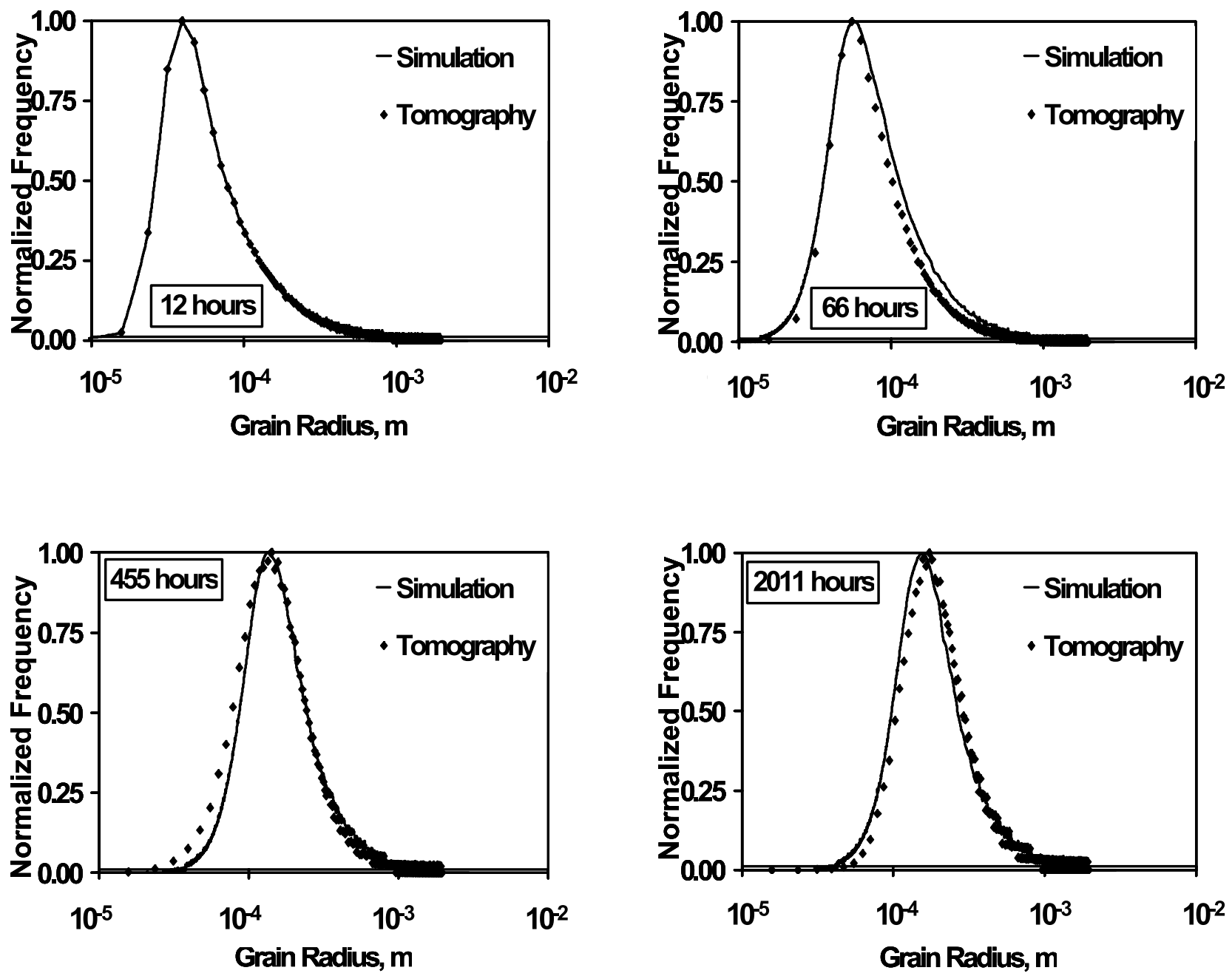

Figure 3. Simulated DRCs from this model (solid line) and experimental DRCs (diamonds) from Flin et al. [2004] in semilog coordinates after 12, 66, 455 and 2011 hours of evolution at $-2^{\circ} \mathrm{C}$. The simulation is initialized with the DRC measured at $\mathrm{t}=12$ hours.

not show any clear trend. We estimate from this set of data that more than $85 \%$ of the structures have a positive curvature. Neglecting the concave structures therefore moderately affects $\mathrm{P}_{\mathrm{av}}$ and consequently leads to a probably modest underestimation of the water vapor fluxes.

[29] The same set of data is again used to test the validity of the model by checking its ability to reproduce the evolution of the experimental DRC. We used as input data in our model the distribution of spherical particles with the very same DRC that was measured by Flin et al. [2004] at time $\mathrm{t}_{1}=12$ hours, using only the convex part. The evolution of this initial set of data was simulated and the curvature distributions obtained after 66, 455, and 2011 hours were compared to the corresponding experimental curves (Figure 3 ). The agreement is remarkably good owing to the drastic simplification of the geometrical description. Even after 2011 hours, no significant bias is observable between the simulated and observed curves.

[30] However, this agreement could be only apparently good. Large structures are not numerous at the beginning of the experiment and large errors in their population could go unnoticed when plotted in a linear scale. Since these large structures become predominant as the evolution goes on, small differences in their populations at short times would produce large errors in the curvature distributions at long times [Snyder et al., 2000]. Figure 4 thus shows the same curves in logarithmic scale to ensure that the populations of very large grains are also well reproduced at any time. The good agreement is confirmed for any grain size. If systematic errors are actually introduced by the geometrical mean field approximation or by the physical assumptions on metamorphism, their effect is not visible on the DRC after 2011 hours evolution, which induced drastic morphological changes, as detailed by Flin et al. [2003].

[31] No other experimental data set is available to confirm these findings, because of the difficulty to obtain highresolution tomographic data. It seems unlikely, however, that such an agreement could be fortuitous. We rather interpret it as evidence that the description of the physics is suitable to predict the evolution of the DRC and the water vapor fluxes between the snow structures. In particular, this implicitly means that the somewhat arbitrary choice of the condensation coefficient $\alpha=1$, yields correct values of the growth rate. According to our simulations, the surface processes are not rate limiting under these conditions. The water vapor fluxes are satisfactorily described by gas phase 

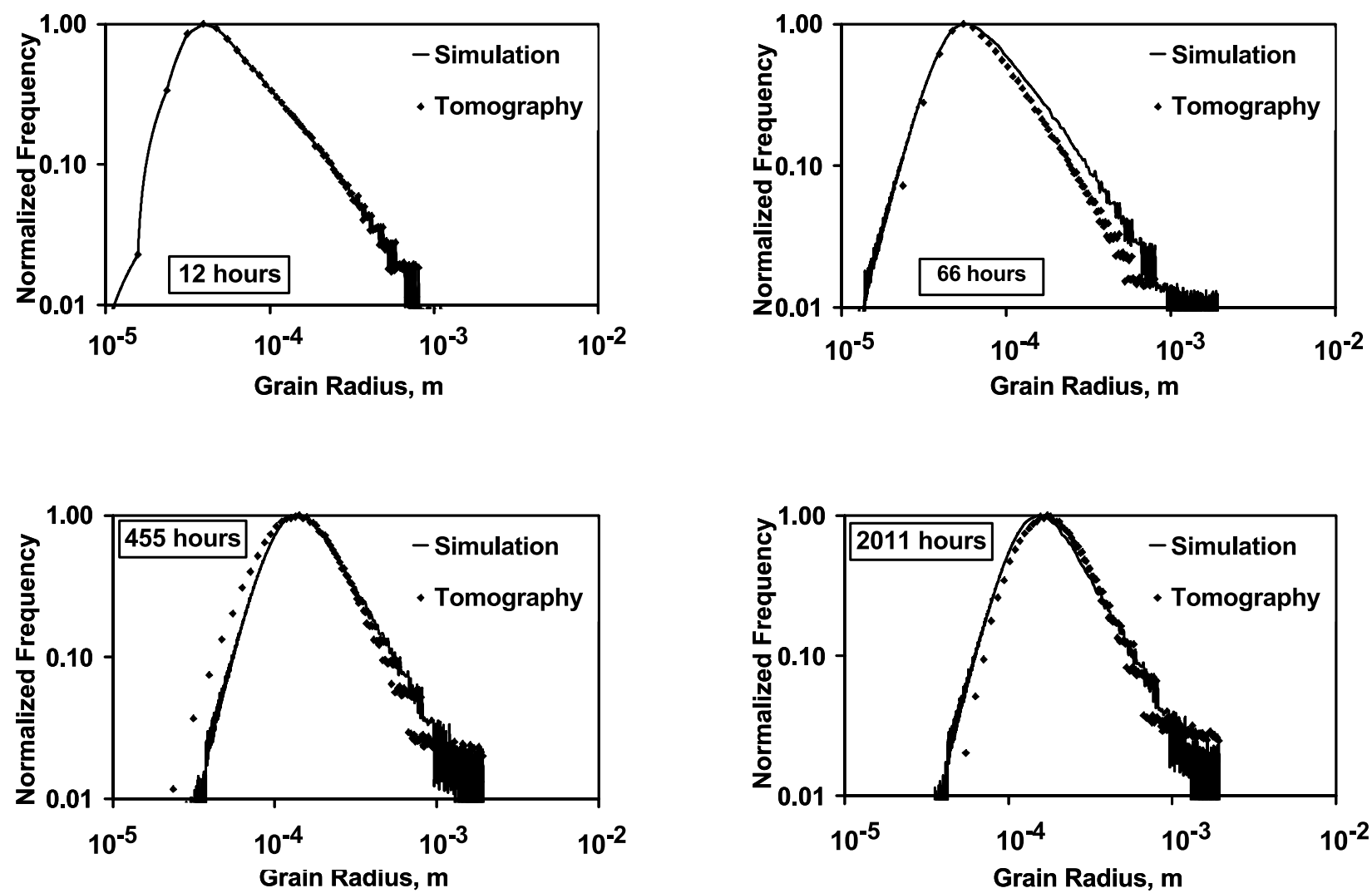

Figure 4. Same as Figure 3 in log-log coordinates. The normalized frequencies can be compared for large and small grains (see text).

diffusion driven by the DRC and independently from the actual 3-D geometry which is not reproduced.

\subsection{Transient Regime}

[32] It has been emphasized in section 2.3 that the shape of the DRC determines $\mathrm{P}_{\mathrm{av}}$, thus the growth rate of an individual grain and finally the evolution of the DRC itself. According to Ostwald ripening theories, the normalized DRC should finally reach the stationary shape that characterizes the steady state regime. We recall that equation (2) gives analytically the rate of SSA decrease during the steady state regime, which is not possible within the transient regime. It is therefore important to test how long is required to reach steady state. In this section, we try to evaluate the duration of the transient regime.

[33] The evolution of the SSA of any real DRC, $\mathrm{SSA}_{\text {real }}$, differs from the evolution of the SSA of the steady state $\mathrm{DRC}, \mathrm{SSA}_{\mathrm{SS}}$, until the end of the transient regime. The two curves of evolution merge at the end of the transient regime and this yields its duration. In the steady state, $\mathrm{SSA}_{\text {real }}$ evolves just like $\mathrm{SSA}_{\mathrm{SS}}$ and follows equation (2). $\mathrm{SSA}_{\text {real }}$ can be obtained from experimental or simulated data and the asymptotical trend at long times of evolution can be fitted to equation (2), to determine the parameters $\mathrm{SSA}_{0}, \mathrm{n}$ and $\tau$. $\mathrm{SSA}_{\mathrm{SS}}$ is then obtained from equation (2). This method was applied to the initial DRC of Flin et al. [2004].

[34] The evolution of their DRC was simulated for extremely long times and the curves of $\mathrm{SSA}_{\text {real }}$ and $\mathrm{SSA}_{\mathrm{SS}}$ were derived as explained above (Figure 5). The transient regime is clearly visible and it lasts more than 1 million days according to these simulations, and the SSA is then about $10 \mathrm{~cm}^{2} \mathrm{~g}^{-1}$, lower than any value measured in seasonal snowpacks [Jordan, 1991; Dominé et al., 2002]. This comforts the assertion from Legagneux et al. [2004] that steady state theories of Ostwald ripening cannot be used to model the SSA decrease of isothermal snow over realistic time scales.

\subsection{Effect of the DRC on the Rate of SSA Decrease}

[35] Natural fresh snows show variable crystal shapes and supposedly variable DRCs that should approach differently the steady state. As discussed above, the rate of SSA decrease depends on the DRC. This rate of decrease was studied experimentally by Legagneux et al. [2003] under isothermal conditions. They showed that it followed a simple logarithmic equation:

$$
S S A=B-A \operatorname{Ln}(t+\Delta t)
$$

where $\mathrm{A}, \mathrm{B}$ and $\Delta \mathrm{t}$ are adjustable parameters. B was then shown to be close to the initial SSA when $t=0$. They obtained an empirical linear relationship between A and B for a given temperature and they suggested that this might be enough to predict reasonably well the evolution of the SSA from the only determination of its initial value. This suggests that the effect of the DRC on the rate of evolution of the SSA is probably limited, or on the contrary that all natural snows have similar DRCs. We thus made simulations to evaluate the sensitivity of the model to the initial DRC. For convenience, we used lognormal test functions 


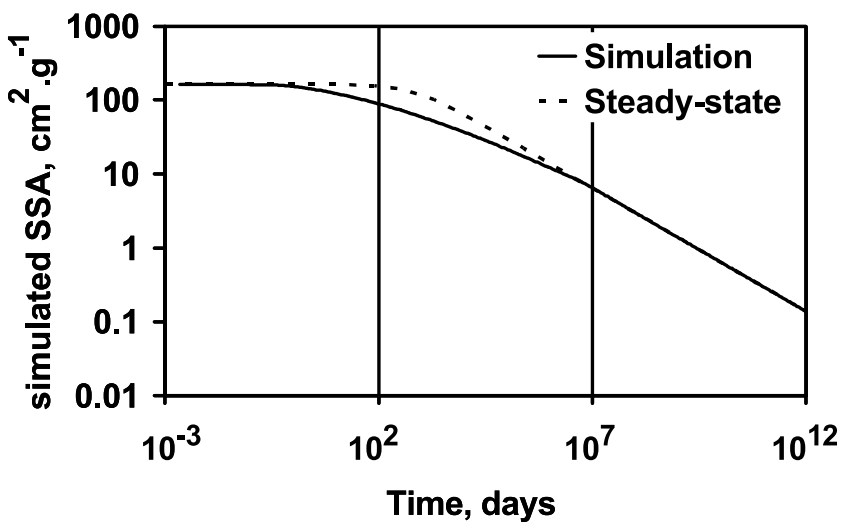

Figure 5. Simulated curve of SSA decrease with the initial DRC from Flin et al. [2004] (solid line) and best fit with equation (2) that describes a steady state evolution (dashed line).

because they yield realistic DRCs and are easily handled, but tests performed with other functions lead to the very same conclusions.

[36] Lognormal initial DRCs of different widths where generated. The width increases with the geometric standard deviation of the lognormal distribution, sigma. The sigma values $1.1 ; 1.4 ; 1.6$ and 1.8 where investigated (Figure 6). The position of the maximum of the lognormal distribution can also be changed. It was adjusted so that all distributions had the same initial SSA: $\mathrm{SSA}_{0}=$ $1600 \mathrm{~cm}^{2} \mathrm{~g}^{-1}$ and all simulations were run under the same conditions. All simulations therefore lead to the same steady state DRC since parameters $\mathrm{SSA}_{0}, \mathrm{n}$ and $\tau$ are identical. The corresponding asymptotic trend of SSA decrease was fitted to equation (3) with constrained values of $\mathrm{SSA}_{0}=1600 \mathrm{~cm}^{2} \mathrm{~g}^{-1}$ and $\mathrm{n}=3$, since diffusion is rate limiting. Figure 7 shows the SSA evolutions in semilogarithmic coordinates where the steady state curve is represented by filled circles. All curves follow different paths until they join at very long coarsening times. As shown on Figure 8, the shapes of DRCs cannot be distinguished at very long coarsening times, since all the DRCs become identical to the steady

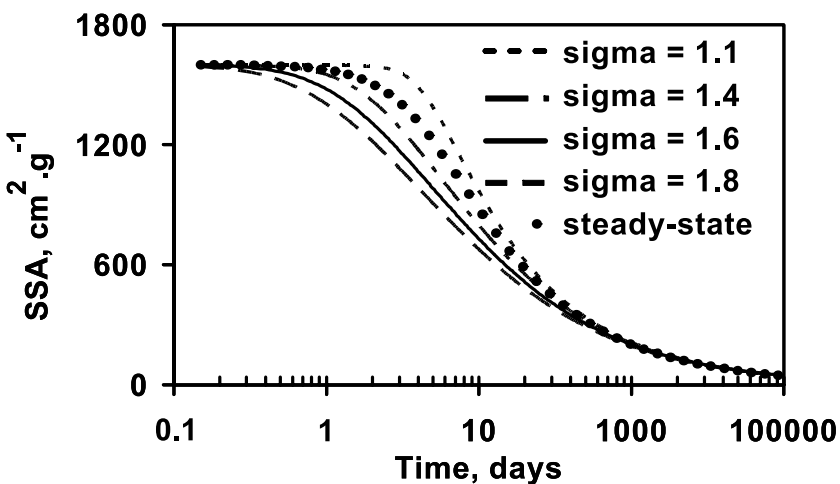

Figure 7. Simulation of the SSA decrease for the initial DRCs plotted in Figure 6. Circles show best fit of the asymptotical evolution with equation (2) that describes a steady state evolution.

state DRC. Figure 8 presents DRCs after 10 million days, because the superposition is almost perfect, but the result is essentially the same after 5000 days.

[37] Depending on the DRC, the transient regime lasts from a about 30 days up to a few years. Broad DRCs cause high curvature and vapor pressure gradients and the small grains sublimate quickly. This explains why their SSA initially decreases rapidly. On the contrary, the large grains do not transform quickly and in any case they do not shrink. That part of the DRC will therefore remain different from that of the steady state DRC until all other grains have grown sufficiently.

[38] As long as the steady state has not been reached, Figure 7 shows that very large variations can be observed between the SSA evolutions. After 5 days, the SSAs range from 800 up to $1200 \mathrm{~cm}^{2} \mathrm{~g}^{-1}$, after 20 days from 570 up to $770 \mathrm{~cm}^{2} \mathrm{~g}^{-1}$ and after 100 days, from 370 up to $450 \mathrm{~cm}^{2} \mathrm{~g}^{-1}$. This represents respectively 40,30 , and $8 \%$ of variability between the simulated curves. The immediate consequence is that, if natural snows have highly variable DRCs as assumed here in our simulations, the knowledge of the initial SSA alone does not yield an accurate prediction of its isothermal evolution for durations equal or less than about 100 days. Unfortunately,

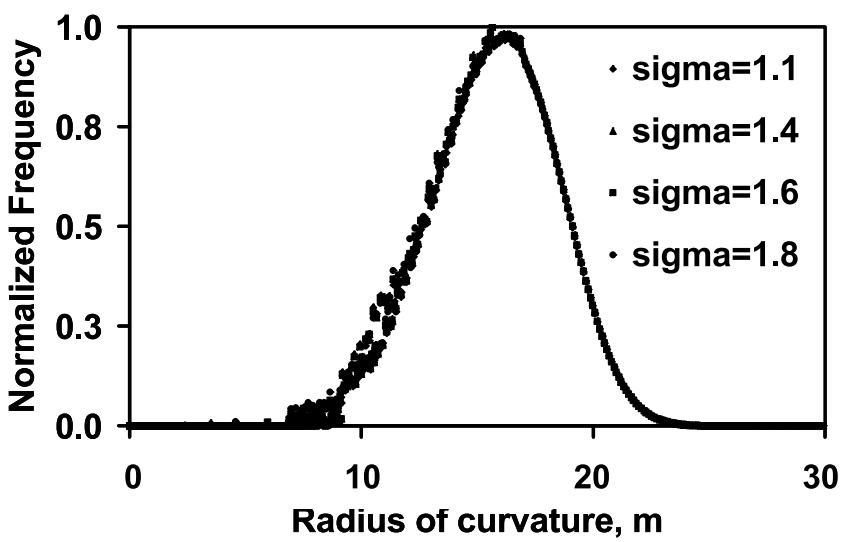

Figure 8. DRCs obtained from the initial lognormal DRCs of Figure 6, after 10 million days of simulated evolution. All DRCs are essentially identical.

Figure 6. Lognormal DRCs of different widths but with the same initial SSA $=1600 \mathrm{~cm}^{2} \mathrm{~g}^{-1}$. 


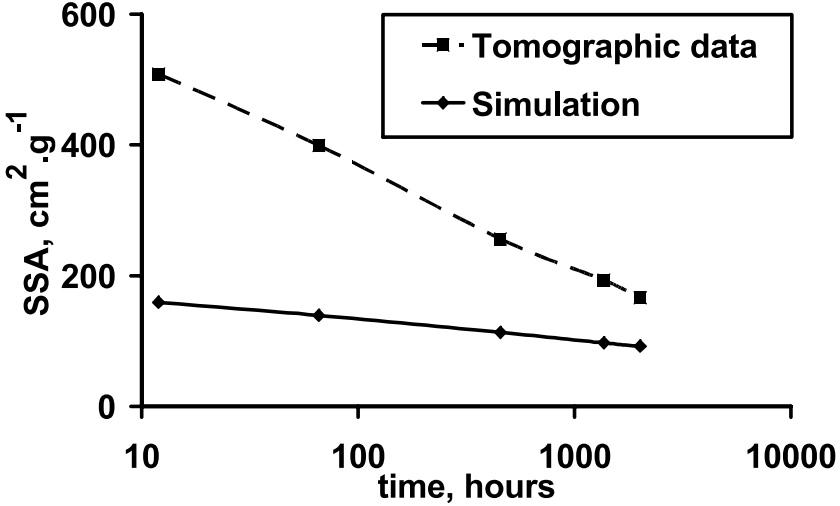

Figure 9. SSA decrease of snow during isothermal conditions at $-2{ }^{\circ} \mathrm{C}$ from simulations (this model) and tomography (data from Flin et al. [2004]).

this is precisely the time scale of interest for studies of seasonal snow packs and especially for atmospheric applications.

[39] According to our simulations, the effect of the DRC on the rate of SSA decrease is real. It has been evaluated with a restricted set of initial DRCs of lognormal shape and showed a significant variability at short times. This variability in the rate of SSA decrease remains however moderate, owing to the large differences imposed between the initial DRCs. On the other hand, the SSA decrease of natural snow samples [Legagneux et al., 2003, 2004] suggested that its rate could be predicted by considering the initial SSA alone. This suggests that the DRC of natural snow is not all that variable. If the DRC of most natural snows can be approximated by a single DRC, we may speculate that this model could estimate satisfactorily the rate of SSA decrease under various conditions of temperature and density, from the simple determination of the initial SSA. However, as we shall see in the next section, another fundamental difficulty is introduced by the description of snow as a distribution of spheres, which prevents us from reaching this goal.

\subsection{SSA and Geometry}

[40] The DRC is essential to model accurately the decrease of the SSA. The experimental DRCs from Flin et al. [2004] are again the only ones available to us but fortunately, they also calculated the decrease of the SSA from their tomographic data. We can then compare their experimental SSA decrease with those derived from our simulations. The SSA is calculated as the ratio of the total surface area to the total mass of the distribution of grains. The simulated and experimental curves of SSA decrease are given in Figure 9. A large gap separates the two curves from the beginning until the end of the experiment. Since the evolution of the shape of the DRC is adequately reproduced, this means that the mass is largely overestimated in our model. The reason obviously lies in the spherical approximation. The spherical shape essentially guarantees the maximum inner volume for a given surface area. However, snow, especially fresh snow, does not consist of disconnected spheres and a shape factor should be introduced to correct the SSA.
[41] The question is, "How should this shape factor be determined?". If the DRCs of all snow types are similar enough, a calibration could be done once and for all on the basis of tomographic observations, to assign a shape factor to each given snow type. However, it is probably not so straightforward. In fact, the grains round off during metamorphism and get closer to the spherical shape, so that the shape factor must vary with time. In fact, the simulations consistently underestimate the SSA by a factor of 4 at the beginning of the experiment and by a factor of 3 after 2011 hours, indicating a change in the shape factor. Indeed, the mass is probably more overestimated for structures of high radius of curvature, such as facets that are frequently seen in fresh snow, than for structures of lower radii of curvature seen after isothermal metamorphism has taken place [Legagneux et al., 2003; Dominé et al., 2003].

[42] The variety of shapes of natural snow crystals and their evolution along with metamorphism make it necessary to introduce a shape factor in the determination of the SSA from the DRC. The geometrical description of snow in our model is therefore too simplified to predict accurately the evolution of the rate of SSA decrease during isothermal metamorphism. However, the physics of isothermal metamorphism seem to be properly described, so that the qualitative effect of parameters such as the temperature $T$, the snow density $\mathrm{d}_{\text {snow }}$ or the condensation coefficient $\alpha$ can be investigated.

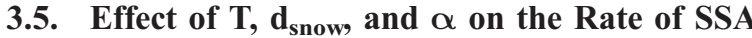 Decrease}

[43] The effects of temperature, snow density and of the condensation coefficient have been tested on fictitious DRCs generated with a lognormal profile. All adjustable parameters of our model of snow metamorphism were set to a fixed level and a single parameter among $\mathrm{T}, \mathrm{d}_{\text {snow }}$ and $\alpha$ was allowed to vary within a reasonable range of values. The temperature range studied is from $233 \mathrm{~K}$ to $271 \mathrm{~K}$, the snow density from 0.01 to 0.4 and the condensation coefficient from $10^{-5}$ to 1 . The curves of SSA decrease are presented in Figures 10, 11, and 12, respectively.

\subsubsection{Effect of Temperature}

[44] The effect of temperature $\mathrm{T}$ is visible in log-log coordinates as a translation of the curve along the time axis

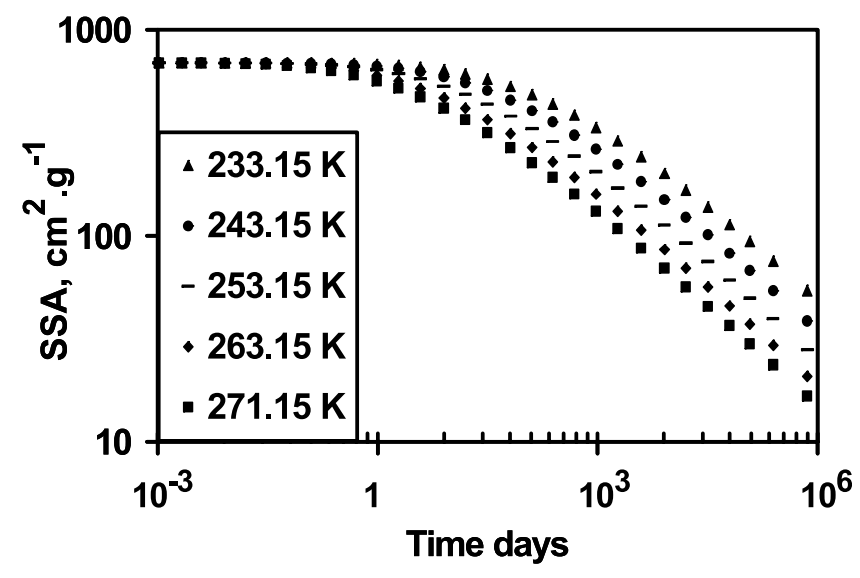

Figure 10. Simulated effect of temperature on the evolution of the SSA, in log-log coordinates. 


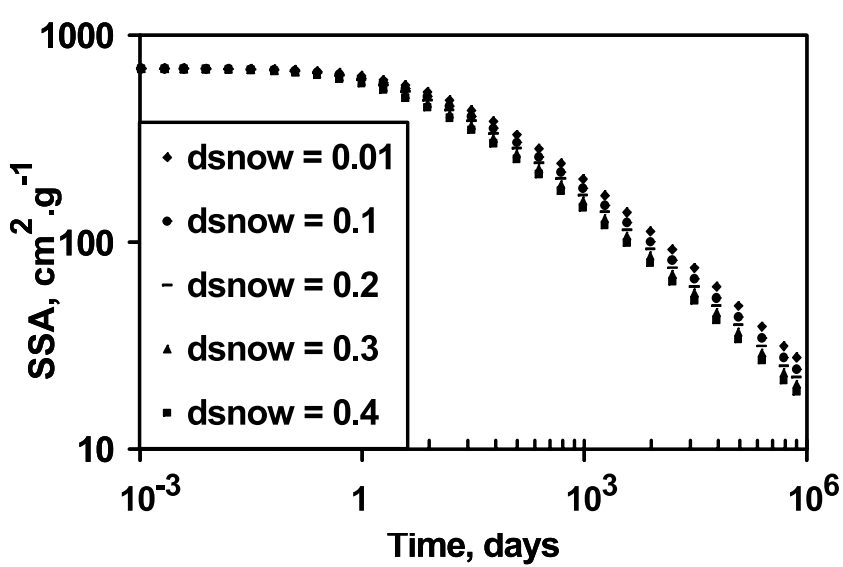

Figure 11. Simulated effect of snow density on the evolution of the SSA, in log-log coordinates.

(Figure 10). This means that the value of $\mathrm{n}$ is constant and equal to 3 and that $\tau$ decreases with $T$. The dependence of $\tau$ with $\mathrm{T}$ according to these simulations is exponential, as can be deduced from equation (10). Indeed, since $\mathrm{P}_{\mathrm{av}}$ depends on $\mathrm{P}_{\text {sat }}$, and since $\mathrm{P}_{\text {sat }}$ has an exponential $\mathrm{T}$ dependence, we expect the growth rate to depend exponentially on $\mathrm{T}$. However, an analytical expression of the T-dependence of the growth rate cannot be obtained, because it depends on the DRC

\subsubsection{Effect of the Snow Density}

[45] The effect of the density of snow on the SSA decrease is visible on Figure 11. However, the magnitude of this effect is less important than that of the temperature. On the other hand, the dependence of $\tau$ with $d_{\text {snow }}$ is not exponential but follows a power law. When the density increases, the sinks and sources of water vapor get closer to each other, which reduces the diffusion length and increases the rate of transfer of water vapor.

[46] This trend is probably correct at the scale of the overall particle distribution but should be considered with much care within a given class of grains, since a density increase has probably more impact on the environment of large grains than on that of small grains. An alternative and perhaps more realistic definition of the cavity size could be reached, stating that the distance of a grain to its sink or source of vapor, i.e., the diffusion length, should not depend on its radius of curvature. This diffusion length would still result from the equality between the experimental snow density and the resulting density of the overall DRC.

\subsubsection{Effect of the Condensation Coefficient}

[47] The effect of $\alpha$ is more complex, as can be seen on Figure 12. No effect is detectable for values of $\alpha$ between $10^{-2}$ and 1 and the slope of the asymptotic curve corresponds to $n=3$. This slope further changes with decreasing values of $\alpha$ between $10^{-2}$ and $10^{-4}$. The parameter $n$ finally stabilizes at 2 for $\alpha$ values below $10^{-4}$ while $\tau$ increases. This can be readily understood as a competition between the surface processes and the diffusion. For $\alpha$ close to 1 , the diffusion of vapor is the rate limiting process. Therefore $n$ asymptotically tends toward 3 and the exact value of $\alpha$ does not impact the rate of SSA decrease. Conversely, for very low values of $\alpha$, the processes of incorporation of molecules from the surface into the bulk control the overall water vapor fluxes. In that case, $\mathrm{n}=2$, in agreement with the results of Wagner [1961]. When surface processes are rate limiting, a slight change in $\alpha$ has clearly a strong impact on the rate of SSA decrease. For intermediate values of $\alpha$, diffusion and surface kinetics both contribute to limit the rate of SSA decrease since none of them is significantly faster than the other one. As we can see from Figure 12, the impact of surface processes should not be detected in the snowpack unless the condensation coefficient is lower than 0.01 . Even for values of $\alpha$ between $10^{-2}$ and $10^{-4}$, the effect of diffusion can be felt and we thus suggest that diffusion cannot be neglected, as assumed by Flin et al. [2003].

[48] The effect of these parameters on the rate of SSA decrease is not fortuitous and results directly from the expression of the growth rate of a single grain (10). This model yields the dependence of the rate of SSA decrease with $\mathrm{T}$ and $\mathrm{d}_{\text {snow }}$ for a given DRC, but again, the geometrical approximations prevent the prediction of this rate, even if the DRC is precisely known. There is thus no point at present in trying to obtain a precise expression of $\tau$.

\section{Conclusions}

[49] Our objective was to test to what extent a mean field model based on the theoretical framework of Ostwald ripening could predict the evolution of the DRC and the SSA of snow under isothermal conditions. The evolution of the DRC is very well reproduced once the initial DRC is known, which validates the description of the physical processes responsible for metamorphism according to Ostwald ripening. In particular, the assumption that the condensation coefficient is equal to unity in the snowpack yields satisfactory results, which demonstrates that diffusion is rate limiting. Conversely, under isothermal conditions, the surface processes are not rate limiting. The topological effect of the immediate environment does not appear essential to calculate the overall rate of evolution either, and the mean field approximation is justified. Other processes [Maeno and Ebinuma, 1983] such as matter transport by surface or volume diffusion can also be neglected in this treatment of the sintering of seasonal snow. Furthermore, it

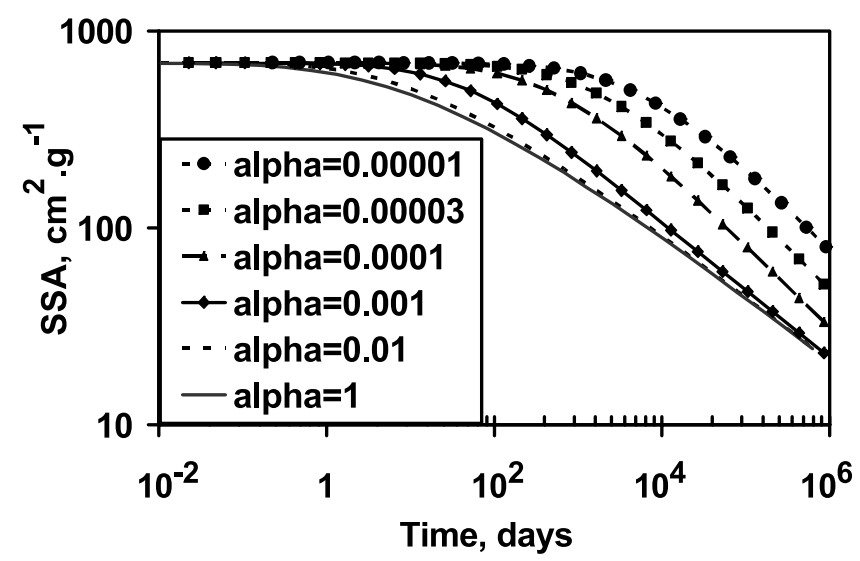

Figure 12. Simulated effect of the condensation coefficient "alpha" on the evolution of the SSA, in log-log coordinates. The slope is $1 / 3$ for high values of alpha and $1 / 2$ for low values of alpha. 
also allows the evaluation of the dependence of the rate of SSA decrease on basic parameters such as temperature and density. This dependence is directly related to equation (10) that describes the growth rate of a single grain, though an analytical expression remains hidden by the collective behavior of the distribution of grains.

[50] However, some important work is still needed to predict accurately the rate of SSA decrease in isothermal snow. Two aspects should be considered. The first one ensues from the experimental data of Legagneux et al. [2004], who showed experimentally that the rate of decrease of snow SSA could be predicted from the initial SSA alone. Since the present work indicates that the DRC will have a strong impact on the rate of SSA decrease, we must come to the conclusion that most snow DRCs are similar. The shape of the DRC should thus be recorded for different snow samples from various snow types to conclude on the existence of a characteristic shape. This would significantly facilitate the description of the structure of snow and its inclusion in models of metamorphism to predict the evolution of SSA. The second one regards the description of the morphology of snow, and its relation with the mass of ice associated with each curvature. This will probably require a great deal of work, but if there are strong constraints on snow crystal shapes, as suggested above, it may turn out that fairly simple relationships can be found between mass and curvature. From this study and the observation of snow crystals, it can already be stressed that the shape factor will depend on the radius of curvature and evolve with time.

[51] It is a long way to reach this goal, but a more direct application is also permitted by the rapidity of this model. Flin et al. [2003] cannot solve for the diffusion field on their 3-D mesh. However, our simulations show that a mean field model adequately reproduces the evolution of the DRC, from which we conclude that the effect of the immediate environment on the average water fluxes toward a grain of a given size is weak. Our mean field model can thus be used to calculate the water vapor fluxes toward the grains. The average effect of the diffusion field can be simulated reasonably well for a low computational cost and the morphological changes followed directly from their 3-D representation.

[52] Finally, even though this work is only a first step toward a difficult goal, we see a possibility that the evolution of snow microphysics can be modeled in a sufficiently simple way that it can be included in coupled snow-atmosphere models. Introducing temperature gradients is a necessary step to reach that goal. It is quite straightforward to replace Kelvin's equation by Clapeyron's equation in the determination of the saturating vapor pressure, but major challenges arise. (1) The condensation coefficient can no more be set equal to 1 ; snow grains grown under temperature gradient metamorphism are facetted which evidences a contribution of surface processes to the growth rate. (2) Such geometrical features also dramatically amplify the importance and the variability of the shape factor. (3) Heat conduction through ice has to be modeled in conjunction with water vapor transfer through air since heat fluxes induced par phase transitions are considerably enhanced under temperature gradient metamorphism. (4) Finally, as evidenced by Yosida et al. [1955] and Colbeck [1983b], vapor transfer becomes more direc- tional, more localized from one grain to another by the socalled hand-to-hand mechanism and therefore more dependent on the immediate environment as the temperature gradients increase, which seems hardly reconcilable with this isotropic mean field model. Nevertheless, relying on our observations of snow metamorphism in natural conditions [Cabanes et al., 2002, 2003] we are confident that the present model should adapt fairly well to conditions of moderate temperature gradients.

[53] Acknowledgments. This work was supported by CNRS through Programme National de Chimie Atmosphérique (PNCA). We thank JeanBruno Brzoska, Frédéric Flin, and coworkers from CEN-Météo France for making their data available prior to publication and for stimulating discussions.

\section{References}

Akaiwa, N., and P. W. Voorhees (1994), Late-stage phase separation: Dynamics, spatial correlations and structure functions, Phys. Rev. E., 49 , $3860-3880$

Akitaya, E. (1974), Studies of depth hoar, Low. Temp. Sci., Ser. A, 26, $1-$ 67.

Albert, M. R. (1996), Modeling heat, mass, and species transport in polar firn, Ann. Glaciol., 23, 138-143.

Arons, E. M., and S. C. Colbeck (1995), Geometry of heat and mass transfer in dry snow: A review of theory and experiment, Rev. Geophys., 33, 463-493.

Baunach, T., C. Fierz, P. K. Satyawali, and M. Schneebeli (2001), A model for kinetic grain growth, Ann. Glaciol., 32, 1-6.

Brailsford, A. D., and P. Wynblatt (1979), The dependence of Ostwald ripening kinetics on particle volume fraction, Acta Metall., 27, 489-497.

Brown, R. L., M. Q. Edens, and A. Sato (1994), Metamorphism of finegrained snow due to surface curvature differences, Ann. Glaciol., 19, 6976.

Brun, E. (1989), Investigation on wet-snow metamorphism in respect of liquid-water content, Ann. Glaciol., 13, 22-26.

Brun, E., E. Martin, V. Simon, C. Gendre, and C. Coleou (1989), An energy and mass model of snow cover suitable for operational avalanche forecasting, J. Glaciol., 35-121, 333-342.

Brun, E., P. David, M. Sudul, and G. Brunot (1992), A numerical model to simulate snow cover stratigraphy for operational avalanche forecasting, J. Glaciol., 38, 13-22.

Brzoska, J. B., B. Lesaffre, C. Coléou, K. Xu, and R. A. Pieritz (1999), Computation of 3D curvature on a wet snow sample, Eur. Phys. J. Appl. Phys., 7, 45-57.

Bullard, J. W. (1997), Numerical simulations of transient-stage Ostwald ripening and coalescence in two dimensions, Mater. Sci. Eng. A, 238, $128-139$

Cabanes, A., L. Legagneux, and F. Dominé (2002), Evolution of the specific surface area and of crystal morphology of Arctic fresh snow during the Alert 2000 campaign, Atmos. Environ., 36, 2767-2777.

Cabanes, A., L. Legagneux, and F. Dominé (2003), Rate of evolution of the specific surface area of surface snow layers, Environ. Sci. Technol., 37, $661-666$.

Colbeck, S. C. (1973), Theory of metamorphism of wet snow, CRREL Res. Rep. 313, Cold Regions Res. and Eng. Lab., Hanover, N. H.

Colbeck, S. C. (1980), Thermodynamics of snow metamorphism due to variations in curvature, J. Glaciol., 26, 291-301.

Colbeck, S. C. (1982), An overview of seasonal snow metamorphism, Rev. Geophys., 20, 45-61.

Colbeck, S. C. (1983a), Ice crystal morphology and growth rates at low supersaturations and high temperatures, J. Appl. Phys., 54, 2677-2682.

Colbeck, S. C. (1983b), Theory of metamorphism of dry snow, J. Geophys. Res., 88, 5475-5482.

Colbeck, S. C. (1986), Classification of seasonal snow cover crystals, Water Resour. Res., 22, 59S-70S.

Colbeck, S. C. (1991), The layered character of snow covers, Rev. Geophys., 29, 81-96.

Colbeck, S. C. (1997), A review of sintering in seasonal snow, CRREL Rep. 97-10, 11 pp., Cold Regions Res. and Eng. Lab., Hanover, N. H.

Colbeck, S. C. (1998), Sintering in a dry snow cover, J. Appl. Phys., 84, 4585-4589.

Colbeck, S. C. (2001), Sintering of unequal grains, J. Appl. Phys., 89, 4612-4618.

Dang, H., C. Genthon, and E. Martin (1997), Numerical modelling of snow cover over polar ice sheets, Ann. Glaciol., 25, 170-176. 
De Hoff, R. T. (1984), Generalized micro-structural evolution by interface controlled coarsening, Acta Metall. Mater., 32, 43-47.

De Hoff, R. T. (1991), A geometrically general theory of diffusion controlled coarsening, Acta Metall. Mater., 39, 2349-2360.

De Quervain, M. R. (1958), On metamorphism and hardening of snow under constant pressure and temperature gradient, IAHS Publ., 46, $225-239$.

Dominé, F., and P. B. Shepson (2002), Air-snow interactions and atmospheric chemistry, Science, 297, 1506-1510.

Dominé, F., A. Cabanes, and L. Legagneux (2002), Structure, microphysics and surface area of the Arctic snowpack near Alert, during Polar Sunrise Experiment 2000, Atmos. Environ., 36, 2753-2765.

Dominé, F., T. Lauzier, A. Cabanes, L. Legagneux, W. Kuhs, K. Techmer, and T. Heinrichs (2003), Snow metamorphism as revealed by scanning electron microscopy, Microsc. Res. Technol., 62, 33-48.

Durand, Y., G. Giraud, E. Brun, L. Merindol, and E. Martin (1999), A computer-based system simulating snowpack structures as a tool for regional avalanche forecasting, J. Glaciol., 45, 469-484.

Fierz, C., and T. Baunach (2000), Quantifying grain shape changes in snow subjected to large temperature gradients, Ann. Glaciol., 31, 439-444.

Flin, F., J. B. Brzoska, B. Lesaffre, C. Coléou, and R. A. Pieritz (2003), Full three-dimensional modelling of curvature-dependent snow metamorphism: First results and comparison with experimental tomographic data, J. Phys. D Appl. Phys., 36, 1-6.

Flin, F., J. B. Brzoska, B. Lesaffre, C. Coléou, and R. A. Pieritz (2004), Three-dimensional geometric measurements of snow microstructural evolution under isothermal conditions, Ann Glaciol., 38, 39-44.

Grenfell, T., and S. G. Warren (1999), Representation of a non-spherical ice particle by a collection of independent spheres for scattering and absorption of radiation, J. Geophys. Res., 104, 31,697-31,709.

Jordan, R. (1991), A one-dimensional temperature model for a snow cover, CRREL Spec. Rep. 91-16, 49 pp., Cold Regions Res. and Eng. Lab., Hanover, N. H.

Legagneux, L., A. Cabanes, and F. Dominé (2002), Measurement of the specific surface area of 176 snow samples using methane adsorption at 77 K, J. Geophys. Res., 107(D17), 4335, doi:10.1029/2001JD001016.

Legagneux, L., T. Lauzier, F. Dominé, W. Kuhs, T. Heinrichs, and K. Techmer (2003), Rate of decay of specific surface area of snow during isothermal experiments and morphological changes studied by scanning electron microscopy, Can. J. Phys., 81, 459-468.

Legagneux, L., A. S. Taillandier, and F. Dominé (2004), Grain growth theories and the isothermal evolution of the specific surface area of snow, J. Appl. Phys, 95, 6175-6184.

Lifshitz, I. M., and V. V. Slyozov (1961), The kinetics of precipitation from supersaturated solid solutions, J. Phys. Chem. Solids., 19, 35-50.

Lundy, C. C., M. Q. Edens, and R. L. Brown (2002), Measurement of snow density and microstructure using computed tomography, J. Glaciol., 48 , $312-316$.

Maeno, N., and T. Ebinuma (1983), Pressure sintering of ice and its implicationto the densification of snow at polar glaciers and ice sheets, J. Phys. Chem., 87, 4103-4110.
Marbouty, D. (1980), An experimental study of temperature-gradient metamorphism, J. Glaciol., 26, 303-312.

Marder, M. (1985), Correlations and droplet growth, Phys. Rev. Lett., 55, 2953-2956.

Marqusee, J. A., and J. Ross (1984), Theory of Ostwald ripening: Competitive growth and its dependence on volume fraction, J. Chem. Phys., 80, 536-543.

Mätzer, C. (2002), Relation between grain size and correlation length of snow, J. Glaciol., 48, 461-466.

Nelson, J. T., and M. B. Baker (1996), New theoretical framework for studies of vapor growth and sublimation of small ice crystals in the atmosphere, J. Geophys. Res., 101, 7033-7047.

Nelson, J. T., and C. Knight (1998), Snow crystal habit change explained by layer nucleation, J. Atmos. Sci., 55, 1452-1465.

Perla, R., J. Dozier, and R. E. Davis (1986), Preparation of serial sections in dry snow specimens, J. Microsc., 141, 111-114.

Raymond, C., and K. Tusima (1979), Grain coarsening of water-saturated snow, J. Glaciol., 22, 83-105.

Schwander, H., B. Mayer, A. Ruggaber, A. Albold, G. Seckmeyer, and P. Koepke (1999), Method to determine snow albedo values in ultraviolet for radiative transfer modeling, Appl. Opt., 38, 3869-3875.

Snyder, V. A., J. Alkemper, and P. W. Voorhees (2000), The development of spatial correlations during Ostwald ripening: A test of theory, Acta Mater., 48, 2689-2701.

Sokratov, S. A. (2001), Parameters influencing the recrystallization rate of snow, Cold Reg. Sci. Technol., 33, 263-274.

Stevens, R. N., and C. K. L. Davies (2002), Self-consistent forms of the chemical rate theory of Ostwald ripening, J. Mater. Sci., 37, $765-779$

Sturm, M. (1989), The role of thermal convection in heat and mass transport in the subarctic snow cover, Ph.D. thesis, Univ. of Alaska Fairbanks, Fairbanks.

Sturm, M., and C. S. Benson (1997), Vapor transport, grain growth and depth-hoar development in the subarctic snow, J. Glaciol., 43, 4259

Voorhees, P. W., and M. E. Glicksmann (1984a), Solution to the multiparticle diffusion problem with applications to Ostwald ripening-I. Theory, Acta Metall., 32, 2001-2011.

Voorhees, P. W., and M. E. Glicksmann (1984b), Solution to the multiparticle diffusion problem with applications to Ostwald ripening-II. Computer simulations, Acta Metall., 32, 2013-2030.

Wagner, C. (1961), Theorie der Alterung von Niederschlägen durch Umlösen, Z. Elecktrochem., 65, 581-591.

Yosida, Z., et al. (1955), Physical studies on deposited snow, Contrib. Inst. Low Temp. Sci., 7, 19-74.

F. Domine and L. Legagneux, Laboratoire de Glaciologie et Géophysique de l'Environnement, CNRS, BP 96, F-38402 St Martin d'Hères Cedex, France. (florent@lgge.obs.ujf-grenoble.fr) 